\title{
A Review of Bunyamwera, Batai, and Ngari Viruses: Understudied Orthobunyaviruses With Potential One Health Implications
}

\author{
M. Fausta Dutuze ${ }^{1,2}$, Manassé Nzayirambaho ${ }^{3}$, Christopher N. Mores ${ }^{1}$ \\ and Rebecca C. Christofferson ${ }^{1 *}$
} 'School of Veterinary Medicine, Louisiana State University, Baton Rouge, LA, United States, ${ }^{2}$ College of Agriculture and
Animal Sciences and Veterinary Medicine, University of Rwanda, Kigali, Rwanda, ${ }^{3}$ School of Public Health, University of
Rwanda, Kigali, Rwanda

OPEN ACCESS

Edited by:

Yashpal S. Malik,

Indian Veterinary Research

Institute (IVRI), India

Reviewed by:

Alex Malogolovkin,

National Research Institute for Veterinary Virology and Microbiology

of Russia, Russia

Kuldeep Dhama,

Indian Veterinary Research

Institute (IVRI), India

*Correspondence:

Rebecca C. Christofferson

rcarri1@/su.edu

Specialty section:

This article was submitted to Veterinary Infectious Diseases,

a section of the journal

Frontiers in Veterinary Science

Received: 21 November 2017

Accepted: 23 March 2018

Published: 12 April 2018

Citation:

Dutuze MF, Nzayirambaho M Mores $C N$ and Christofferson $R C$ (2018) A Review of Bunyamwera,

Batai, and Ngari Viruses:

Understudied Orthobunyaviruses With Potential One Health Implications.

Front. Vet. Sci. 5:69.

doi: 10.3389/fvets.2018.00069
Bunyamwera (BUNV), Batai (BATV), and Ngari (NRIV) are mosquito-borne viruses of the Bunyamwera serogroup in the Orthobunyavirus genus of the Bunyaviridae family. These three viruses have been found to cause disease in both livestock animals, avian species, and humans. Thus, these viruses pose a potential threat to human public health, animal health, and food security. This is especially the case in the developing nations, where BUNV and NRIV are found, mainly in Africa. BUNV and BATV are fairly well characterized, while NRIV is not well characterized owing to only sporadic detection in human and animal populations in Africa. Reassortment is common among bunyaviruses, but NRIV is believed to be the only natural reassortant of the Bunyamwera serogroup. It resulted from a combination of BUNV $S$ and $L$ segments and the BATV $M$ segment. This indicates at least some level co-circulation of BUNV and BATV, which have no historically been reported to overlap in geographic distributions. But as these viruses are undercharacterized, there remains a gap in the understanding of how such reassortment could occur, and the consequences of such. Due to their combined wide range of hosts and vectors, geographic distributions, potential severity of associated diseases, and potential for transmissibility between vertebrate hosts, these viruses represent a significant gap in knowledge with important One Health implications. The goal of this review is to report available knowledge of and identify potential future directions for study of these viruses. As these are collectively understudied viruses, there is a relative paucity of data; however, we use available studies to discuss different perspectives in an effort to promote a better understanding of these three viruses and the public and One Health threat(s) they may pose.

\section{Keywords: Orthobunyavirus, Bunyamwera virus, Ngari, Batai, Rwanda, arboviruses of cattle}

\section{INTRODUCTION}

Bunyamwera virus (BUNV), Batai virus (BATV), and Ngari virus (NRIV) are members of the Bunyamwera serogroup in the Orthobunyavirus genus of the Bunyaviridae family (1-5). They are thought to be primarily transmitted by mosquitoes. BUNV and NRIV are widely distributed throughout large parts of Africa, while BATV is found throughout Asia and Europe (Figure 1; Table S1 in Supplementary Material). The genome structure is a single-stranded, negative sense, 


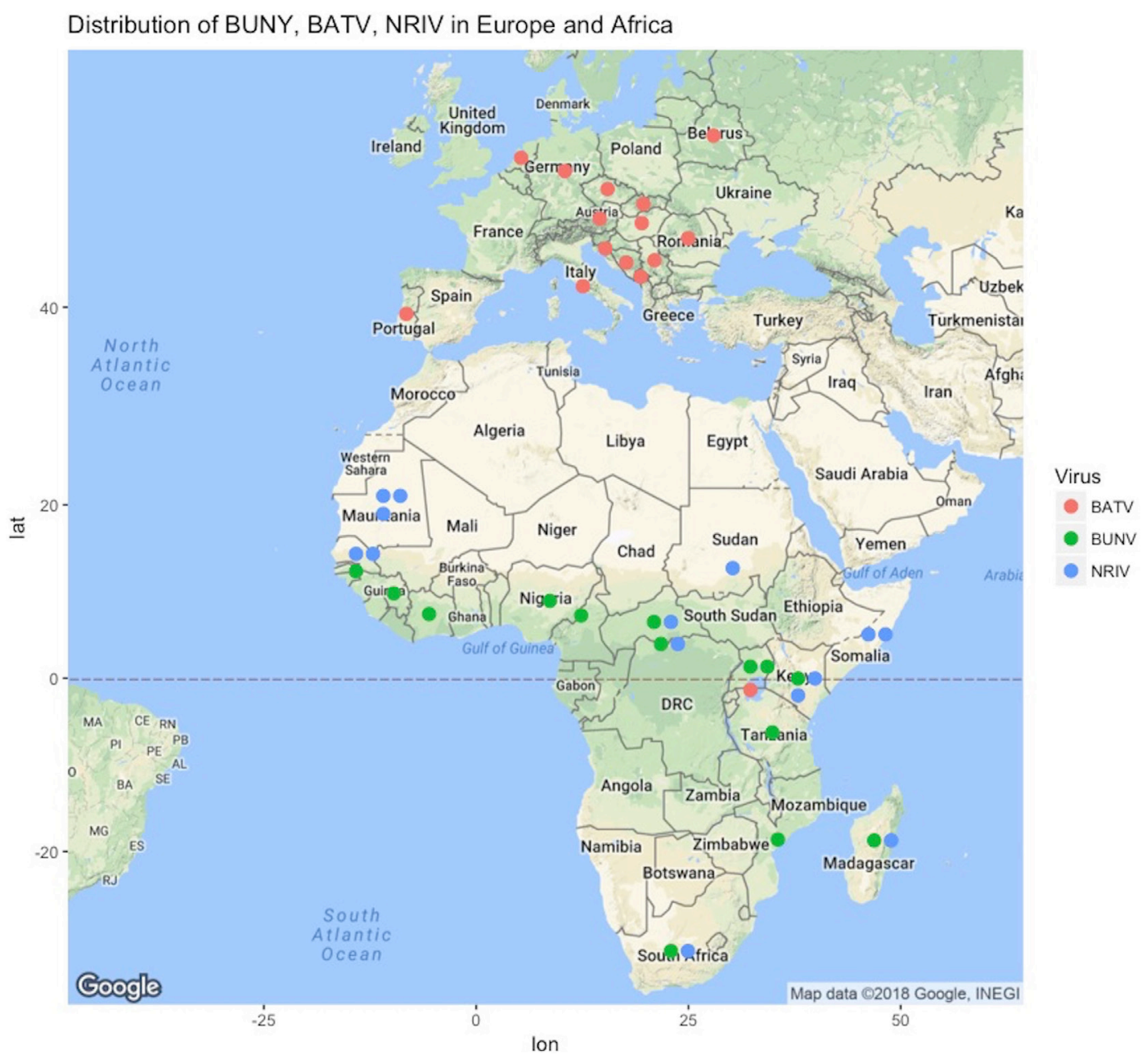

FIGURE 1 | Geographic locations of reports of Bunyamwera (green dots), Ngari (blue dots), and Batai (green dots) across Europe and Africa from literature or ProMED-Mail (http://www.promedmail.org). Not shown are periodic isolations in Russia, India, Malaysia, and China, as well as Cache Valley Fever Virus in North America and the years of report, which are given in Table S1 in Supplementary Material.

tri-segmented RNA: small (S), medium (M), and large (L) that respectively encode the nucleocapsid, envelope glycoprotein, and polymerase protein. Additionally, the $\mathrm{S}$ and $\mathrm{M}$ segments encode non-structural proteins (NSs) (3-6). Reassortments are relatively common among Bunyaviridae family members and even within the Orthobunyavirus genus, but NRIV is the only naturally occurring reassortment in the Bunyamwera serogroup, though experimental reassortants have been derived (1, 7-10). Evidence suggests that NRIV arose from a natural reassortment event resulting from co-infection of BUNV and BATV, as NRIV possesses the $\mathrm{M}$ segment of BATV combined with the $\mathrm{S}$ and $\mathrm{L}$ segments from BUNV $(1,3,11)$.

Bunyamwera virus, BATV, and NRIV are etiological agents of diseases in humans and domestic animals. The disease associated with BUNV has been reported to cause mild symptoms, such as fever, joint pain, and rash in many mammals, including humans $(2,12-14)$. BATV causes a mild flu-like illness in humans, is associated with a more severe disease in ruminants where it is manifested by abortions, premature births, and genetic defects $(12,15,16)$. NRIV has been associated with fatal hemorrhagic fevers in both humans and ruminants $(4,17)$.

Bunyamwera virus is considered the prototype of the Bunyaviridae family, as it is the most characterized $(18,19)$. BATV is also relatively well studied given its wide distribution across Europe and Asia, while NRIV is the least studied of the three $(1,15)$. Studies of NRIV have been focused on genomic comparisons with other Bunyamwera group viruses (BUNV, BATV, and Ilesha viruses) and the similarity of its clinical manifestations with rift valley fever virus (RVFV) $(1,3)$. RVFV is an important virus of the Bunyaviridae family in the Phlebovirus genus, which is associated with abortions in ruminants (cattle, goats, and sheep) and mild (flu-like) to severe (hemorrhagic fever, encephalitis, and ocular troubles) symptoms in humans and ruminants. RVFV causes large outbreaks on the African continent and Arabian Peninsula and is a major public health and food security concern (4, 20-23).

Ngari virus is of particular public health relevance as it was identified as other etiologies of febrile illnesses in humans in 
Sudan, Somalia, and Kenya outbreaks in 1988, 1997, and 1998, respectively $(1,4,5,24)$. In these instances, molecular-based techniques, such as nucleic acid amplification and sequencing, were rarely used and diagnosis was based on clinical manifestations, thus the disease was diagnosed as the most common febrile illnesses $(1,4,5,24)$. Consequently, in the Sudanese outbreak, the disease was improperly diagnosed as malaria, as in malaria-endemic countries $70 \%$ of febrile illnesses are treated as presumptive malaria, often without proper medical examination and a laboratory analysis (25). In Somalia and Kenya, as it was during an ongoing RVFV, the disease was mistakenly taken for RVFV. Thus, the burden of disease of NRIV and likely BUNV and BATV as well is underreported and their public health impact under-appreciated.

While these viruses have heretofore been primarily identified in Europe and Asia (BATV) and Africa (BUNV and NRIV), there is a potential for worldwide spread. This is more evident as global trade and travel move people and goods around the world at records rates and continued development and urbanization bring domesticated animals and humans into greater contact with potential cryptic zoonotic transmission cycles. The two most recent importations of Old World viruses into the Western Hemisphere-chikungunya and Zika-highlight this risk $(26,27)$. When these viruses were introduced, millions were infected in record time, as there was no prior immunity to impede transmission through human populations. Similarly, there is not much known regarding the potential for herd health against these viruses in human and animal populations in the Western Hemisphere, though there is evidence to suggest that Orthobunyaviruses of the New World would offer some potential for cross-protection (28).

The aim of this review is to compile the available knowledge on these three viruses (BUNV, BATV, and NRIV) in an effort to identify potential future lines of investigation to fill any gaps. Fundamental concepts will be described and, where data permits, different perspectives discussed. Emphasis will be made on the relationships among molecular characteristics, transmission mechanisms, geographic distributions, and clinical manifestations among the three viruses, as well as with other related viruses. We performed comprehensive searches in PubMed and Google Scholar by searching for material related to BUNV, BATV, and NRIV epidemiology, vector competence, field studies/cases, and laboratory characterization studies. References relevant to the three viruses were included and exclusion of material was for redundancy (reviews, e.g.).

\section{ORIGINS AND GEOGRAPHIC DISTRIBUTIONS OF BUNV, BATV, AND NRIV}

Bunyamwera virus was first isolated in 1943 from Aedes mosquitoes collected in the Semliki Forest, Uganda as part of a yellow fever surveillance effort $(13,18,29)$. BUNV is now considered endemic in several African countries, such as Uganda, Tanzania, Mozambique, Nigeria, Guinea, South Africa, and Democratic Republic of Congo (Figure 1). Recently, Cache Valley Fever virus was classified as a strain of BUNV, which expands the overall geographic range to North America, and additional strains of BUNV have been isolated in Argentina (2). A recent compilation of studies reported the presence of BUNV in Senegal, Guinea, Ivory Cost, Nigeria, Cameroon, Central African Republic, Kenya, Uganda, South Africa, and Madagascar (30).

Ngari virus was first isolated from Aedes simpsoni mosquitoes in 1979 in Southeastern Senegal. It was then recovered from several mosquito species in Senegal, Burkina Faso, Central African Republic and Madagascar (1988-1993) (31). The first suspicion of its potential pathogenicity in humans was when the virus was isolated from two patients in Dakar in October and November 1993 (31). In Kenya and Somalia (1998-1999), the Garissa strain of NRIV was identified in what was thought to be a RVFV outbreak, owing to the hemorrhagic manifestations of infection (4). In 2010, during an ongoing RVFV outbreak in Mauritania, NRIV was again isolated in goats (32). NRIV has additionally been isolated in Burkina Faso, Central African Republic, and Madagascar (30). In all these cases, microscopy, RT-PCR, and complete nucleotide sequences were used in the differential diagnostic panels and confirmed the differentiation between other Bunyaviruses (BUNV, BATV, ILEV, and RVFV) as well as other suspected agents (malaria) $(3,4,32)$.

Batai virus is one of the most geographically widespread members of the Orthobunyavirus genus (Figure 1) $(1,33)$. It also has the most broad vector range as it was isolated from Anopheles maculipennis in Czechoslovakia in 1950, from Culex gelidus Theo mosquitoes in Malaysia, from Anopheles barbirostris mosquitoes in Chittoor district in India, and from A. maculipennis and Aedes punctor mosquitoes collected in what is modern Ukraine $(1,18$, 34-37). In Europe, evidence for circulation exists in Norway, Sweden, Finland, Slovakia, the Czech Republic, Croatia, Serbia, Bosnia, Montenegro, Italy, Hungary, Romania, Austria, Portugal, Germany, and Belarus (38). The seroprevalence reported in humans in Europe is low: less than $1 \%$ in Sweden, Finland, Germany, Austria, and parts of the former Yugoslavia. However, there was a $32 \%$ seroprevalence reported in southern Slovakia (15). Similarly, seroprevalence in animals varied from 1 to $46 \%$ (15). Interestingly, BATV is not widely reported on the African continent, having only been reported in Uganda (1). However, the distribution of NRIV as well as the presence of suitable hosts and vector suggests that BATV might be present in other African countries and be underreported, or at least has the potential to be so.

Although no research has been conducted on the asymptomatic presentation of BUNV, BATV, and NRIV infections in vertebrate hosts, other arboviral viruses across several genera are known to present as mostly asymptomatic or as a mild influenzalike illness (39). Therefore, it is possible that NRIV, BUNV, and even BATV were circulating before successful isolation and that they may silently circulate in many areas, where no serological studies have been conducted that may detect asymptomatic or mild, generalized disease.

Ngari virus was isolated 35 years ago, nearly 30 years after the parental viruses, BUNV and BATV. Given the geographical history of BUNV and BATV, the speculation is that the first reassortment leading to new viral progeny likely resulted from the introduction of BATV into the population of already-circulating BUNV 
in Africa. Many factors may have contributed to the introduction of BATV in East Africa, likely long-distance bird migration (40). But these distinct geographies of BATV and BUNV also suggest that NRIV likely has developed its own niche and propogates as a distinct virus rather than relying on repeated introductions and chance co-infections of BATV and BUNV in the wild.

\section{CLASSIFICATION, GENOMIC CHARACTERISTICS, AND REPLICATION IN HOST CELLS}

\section{Classification}

The Bunyamwera group is one of 18 serologically defined arbovirus serogroups belonging to the Orthobunyavirus genus of the family Bunyaviridae (16). The 18 serogroups are Anopheles A, Anopheles B, Bakau, Bunyamwera, Bwamba, group C, Capim, California, Gamboa, Guama, Koongol, Minatitlan, Nyando, Olifanstlei, Patois, Simbu, Tete, and Turlock (41). The viruses of this genus have been classified into these different serogroups based on serological relationships of complement fixing antibodies, as well as hemagglutinating assay results and neutralizing antibodies (42).

The classification of the Bunyaviridae family has evolved, since its first organization in 1971 when the Subcommittee on Interrelationships Among Catalogued Arboviruses (SIRACA) conducted a serological study of 23 viruses. They subsequently classified 14 viruses as belonging to the Bunyamwera group viruses and further identified five subgroups or complexes: Bunyamwera, Cache Valley, Wyeomyia, Kairi, and Guaroa (43). In 1978, this classification was updated based on the antigenic relationships of Bunyamwera group viruses established by the cross-neutralization pattern of virus-specific hyperimmune antibodies $(44,45)$. From this effort emerged three subgroups that diverge largely over geographic origin: South America, Africa, and Europe/Asia (of which BATV is the only member) (28). While there was very little cross-neutralization among members of the South-American and African subgroups, BATV is crossneutralized by other virus-specific antibodies from the other two subgroups (28). As of 1996, there are over 30 Bunyamwera serogroup viruses that have been identified and classified (46). As mentioned, CVV was also recently reclassified as a strain of BUNV (2). Table 1 shows the 32 Bunyamwera group viruses and the geographic areas, where they were first isolated, as well as their main vertebrate hosts and principal vectors. Most of the Bunyamwera serogroup viruses are etiological agents of human and animal diseases (5, 13, 47-49).

The taxonomy of Bunyaviruses has been challenging, given the propensity for reassortment, their general lack of characterization, and the broad geographic ranges of some genera. Often, taxonomy is first developed based on antigenic relationships, but is becoming more molecular-based as genomic methods become cheaper and data becomes available (53). Recently, the International Committee on Taxonomy of Viruses proposed an alternate classification system (54), whereby the family of Bunyavirus was suggested to become a new order Bunyavirales. Orthobunyaviruses would then be classified into the new family
Peribunyaviridae and Orthobunyavirus would remain the genus. Further, Ngari, Bunyamwera, and Batai would no longer be considered separate species, but sub-types of the single species "Bunyamwera orthobunyavirus." This method of classification was not suggested for Flaviviruses. A similar classification of Flaviviruses would have West Nile virus (WNV), dengue virus, and Yellow Fever all become sub-species when these viruses have very different geographic ranges, host ranges, clinical presentation, and within vector dynamics. As Bunyaviruses are often less characterized than Flaviviruses, there is not enough phenotypic data available to determine whether the grouping of many viruses as a single species "Bunyamwera orthobunyavirus" would be appropriate, and further efforts should be made to characterize these viruses to support taxonomic classification methods.

\section{Genomic Characteristics}

As with all Bunyaviruses, BUNV is a segmented negative sense RNA virus. As stated, the genome is composed of three segments $\mathrm{S}, \mathrm{M}$, and L. Each segment is transcribed individually to give a single mRNA. Although there are differences in the sizes of the segments among different species and among strains within species, the averages for Orthobunyaviruses are $6.9 \mathrm{~kb}$ for L segment, $4.5 \mathrm{~kb}$ for $\mathrm{M}$ segment, and $1.0 \mathrm{~kb}$ for S segment $(55,56)$.

The $\mathrm{S}$ segment encodes the $\mathrm{N}$ (nucleocapsid) protein and a NSs, which are translated from overlapping open reading frame in the same mRNA by leaky ribosomal scanning $(6,55,57,58)$. The M mRNA encodes a polyprotein that is post-translationally cleaved by host proteases into NS, and glycoproteins (Gn and Gc) $(6,59,60)$, and the L mRNA encodes the RNA-dependent RNA polymerase $(55,58,61)$. As in other Bunyaviruses genera (Nairovirus and Phlebovirus), NSs and NSm have been shown to be closely related to the pathogenicity and propagation the viruses in vertebrate cells $(53,62)$. Although NSs is encoded by all three viruses, the length of this gene can vary among the genus (55).

The coding sequences are generally less conserved than the untranslated regions (UTRs). The functional promoter is formed by the $5^{\prime}$ and $3^{\prime}$ UTRs of each segment (55, 63-65). 3' and 5' UTRs are complementary (55). The deletion of internal sequences in the UTRs of BUNV resulted in attenuation of virus replication and loss of cytopathogenicity in mammalian cell culture, but the mechanistic basis of this remains unclear $(55,66)$.

Like other Orthobunyaviruses, Bunyamwera serogroup viruses are able to increase genetic and phenotypic diversity through reassortment of genome segments during mixed infections with viruses of the same group $(7,67)$. For example, reassortment between Bunyamwera, Maguari, Batai, and Northway viruses were obtained in cell cultures (68). NRIV is a naturally occurring reassortment resulting from a BUNV and BATV co-infection, though it is unknown whether this co-infection was in the vector or a vertebrate host $(3,31)$. The $\mathrm{L}$ and $\mathrm{S}$ segments of NRIV are from BUNV and the $M$ segment from BATV ( $\left.\mathrm{S}_{\mathrm{BUNV}}, \mathrm{M}_{\mathrm{BATV}}, \mathrm{L}_{\mathrm{BUNV}}\right)$ (31). There are 93\%, 97-98\%, and 89-95\% nucleotide sequences homologies respectively between BUNV and NRIV S segments; BUNV and NRIV L segments; and between BATV and NRIV M segments $(1,3)$. Little is known about the roles of different factors related to the occurrence of the reassortment events, such as host species, viral titers, and viral strains. 
TABLE 1 | The 32 viruses of the Bunyamwera group, geographic areas of origin, main hosts, and principal vectors, including relevant references.

\begin{tabular}{|c|c|c|c|c|c|}
\hline Virus & Abbreviation & $\begin{array}{l}\text { Source, location, year of } \\
\text { first isolation }\end{array}$ & Main hosts & Principal arthropod vectors & Reference \\
\hline AG83 1746 & & South America & Rodents & Mosquitoes & $(46)$ \\
\hline Anhembi & AM & Brazil & Not known & Mosquitoes (culicine) & $(28,46)$ \\
\hline Batai & BAT & $\begin{array}{l}\text { Anopheles maculipennis, } \\
\text { Czechoslovakia, } 1950\end{array}$ & $\begin{array}{l}\text { Humans, ruminants, sentinel } \\
\text { animals (birds) }\end{array}$ & $\begin{array}{l}\text { Mosquitoes (anopheline, culicine), } \\
\text { Biting midges }\end{array}$ & $(28,34,46)$ \\
\hline BeAr 3282208 & & South America & Not known & Mosquitoes & $(46)$ \\
\hline Birao & $\mathrm{BIR}$ & $\begin{array}{l}\text { Anopheles pharoensis, Central Afr. } \\
\text { Rep., } 1969\end{array}$ & Not known & Mosquitoes (anopheline) & $(28,34,46)$ \\
\hline Bozo & & Africa & Not known & Mosquitoes (anopheline, culicine) & $(46)$ \\
\hline Bunyamwera & BUN & Aedes spp., Uganda, 1943 & Humans & Mosquitoes (anopheline, culicine) & $(28,34,46,50)$ \\
\hline Cache valley & CV & Culiseta inornata, Utah, 1956 & Sheep, cattle, marsupials & Mosquitoes (anopheline, culicine) & $(28,34,46)$ \\
\hline CbaAr426 & & South America & Not known & Mosquitoes & $(46)$ \\
\hline Fort Sherman & & Human, Panama, 1985 & Humans & Mosquitoes & $(34,46)$ \\
\hline Germiston & GER & South Africa & Humans, rodents, sentinel animals & Mosquitoes (culicine) & $(28,46)$ \\
\hline Guaroa & GRO & Colombia & Humans & Mosquitoes & (28) \\
\hline laco & & South America & Not known & Mosquitoes (culicine) & $(46)$ \\
\hline Ilesha & ILE & Human, Nigeria, 1957 & Humans & Mosquitoes (anopheline) & $(28,34)$ \\
\hline Kairi & $\mathrm{KRI}$ & Trinidad & $\begin{array}{l}\text { Equine, primates, rodents, sentinel } \\
\text { animals }\end{array}$ & Mosquitoes (culicine) & $(46)$ \\
\hline Lokern & LOK & USA & Cattle, goats, sheep & $\begin{array}{l}\text { Mosquitoes (anopheline, culicine), } \\
\text { Culicoid flies }\end{array}$ & $(28,46)$ \\
\hline Macaua & & South America & Rodents, bats & Mosquitoes (culicine) & $(46)$ \\
\hline Maguari & MAG & Aedes scapularis, Ecuador, 1974 & Sentinel animal, cattle & Mosquitoes (anopheline, culicine) & $(28,34,46)$ \\
\hline Main drain & MD & USA & Equine & Mosquitoes (culicine), Culicoid flies & $(28,46)$ \\
\hline Mboke & & Africa & Not known & Mosquitoes (culicine) & $(46)$ \\
\hline Ngari & & Aedes simpsoni, Senegal, 1979 & Humans & $\begin{array}{l}\text { Mosquitoes (anopheline, culicine), } \\
\text { ticks }\end{array}$ & $(31,46,50,51)$ \\
\hline Northway & NOR & Aedes spp., Alaska, 1971 & Rodents, sentinel animals & Mosquitoes (culicine) & $(28,34)$ \\
\hline Playas & & South America & Not known & Mosquitoes (culicine) & $(52)$ \\
\hline Potosi & & Aedes albopictus, Missouri, 1989 & Not known & Mosquitoes & $(34,52)$ \\
\hline Santa Rosa & & North America & Not known & Mosquitoes (culicine) & $(28)$ \\
\hline Shokwe & & Aedes cumminsii, South Africa, 1962 & Humans, rodents & Mosquitoes (anopheline, culicine) & $(28,34,46)$ \\
\hline Sororoca & SOR & Brazil & Not known & Mosquitoes (culicine) & $(28,46)$ \\
\hline Tensaw & TEN & USA & $\begin{array}{l}\text { Rodents, sentinel } \\
\text { animals, cattle }\end{array}$ & Mosquitoes (anopheline, culicine) & $(46)$ \\
\hline Tlacotalpan & TLA & Mexico & Not known & Mosquitoes & $(28,46)$ \\
\hline Tucunduba & & Brazil & Not known & Mosquitoes & $(28,46)$ \\
\hline Wyeomyia & WYO & $\begin{array}{l}\text { Wyeomyia melanocephala, } \\
\text { Colombia, } 1940\end{array}$ & Not known & Mosquitoes (anopheline, culicine) & $(28,34,46)$ \\
\hline Xingu & & Human, Brazil, unknown date & Humans & Mosquitoes & $(34,52)$ \\
\hline
\end{tabular}

Indeed, the lack of understanding of the genomic variability of these viruses, especially NRIV, means that we are unable to really understand the phylogenetic relationships among species and strains of species, and thus we cannot fully appreciate the processes that promote reassortant and the extent of propagation of such strains. Similar challenges exist for related Bunyaviruses, such as Nairovirus, and recent efforts have established new species and that there is some plasticity to classification of Bunyaviruses related in large part to the lack of comprehensive sequence data (53).

\section{Replication in Host Cells}

Bunyaviridae are enveloped viruses that replicate in the cytoplasm of mammalian cells and bud into the Golgi apparatus
$(68,69)$. Host cell entrance is by clathrin-dependent endocytosis and vacuolar acidification, though the receptors, cellular factors, and specific pathways are not well understood (11, 70-73). The two envelope glycoproteins Gc and Gn are responsible for viral attachment and acid-activated penetration (74). It has been reported that the entry of Germiston and LaCrosse viruses, two other Orthobunyaviruses, is promoted by DC-SIGN (Dendritic cell-specific intracellular adhesion molecule-3-grabbing non integrin) receptors, which is seen in other Bunyaviruses, like the Phleboviruses (75). These receptors are found in dermal dendritic cells and may play a role in viral entry into mammalian cells following transmission by an arthropod bite $(62,74)$.

As with many arboviruses, in vitro infection is generally lytic in mammalian cell lines, while these viruses produce a persistent 
infection in mosquito cells with a lack of cytopathology $(18,76)$. In vitro infection of Aedes aegypti cells with BUNV revealed that NSs are essential for viral replication, as these cells were refractory to infection with a recombinant NSs gene deletion strain (rBUNdelNSs2) $(18,76)$. Further infections of Aedes albopictus cell lines with both a wild-type BUNV and another recombinant NSs gene deletion strain showed that the wild-type strain demonstrated greater fitness with 100-fold higher titers (18). In mammalian cell lines, NSs are also implicated in pathogenesis, as NSs induced shut-off of host protein synthesis and resulted in cell death $(2,18,24)$.

Infection of BHK cells first showed cytopathic effect at $3 \mathrm{~h}$ postinfection. Using Vero cells, most BUNV group members produce clear plaques within 4 days (33). BUNV isolates were shown to grow to higher titers than NRIV isolates (11). Additionally, after serial passage on Vero cells, NRIV was found to have total conservation of N and NSs proteins, while nucleotide substitutions were observed in both the $\mathrm{S}$ and $\mathrm{M}$ segments of subsequent passages of BUNV, which may suggest that the NRIV genome is more stable in Vero cells than its parent BUNV (11).

Persistent infection in C6/36 cells is not associated with cytopathic effects and can last indefinitely. Persistent infection in mammalian cells or long-term infection in mammalian cells or culture media without cells has been noted in other Bunyaviridae viruses, but has not been reported for Orthobunyaviruses $(69,77)$.

\section{TRANSMISSION}

Bunyamwera virus is likely maintained in nature by bloodfeeding mosquitoes and susceptible vertebrate hosts. Evidence suggests Ae. aegypti might be the primary mosquito vector $(2,50)$. Experimental studies showed that Ae. aegypti was competent to transmit BUNV, but not a competent vector for NRIV. However, Anopheles gambiae Giles was competent for both viruses, while Culex quinquefasciatus did not demonstrate competence to transmit any of the two viruses (50). The two identified NRIV outbreaks of human febrile illnesses (Sudan in 1988 and SomaliaKenya in 1997-1998) coincided with episodes of unusually heavy rains and extensive flooding in areas normally arid (1). This seasonal emergence pattern resembles that of RVFV, the primary vector of which is Ae. aegypti $(21,78)$.

Ngari virus has been isolated in many mosquito vectors, such as Aedes argenteopunctatus, Aedes minutus, Aedes vexans, Aedes mcintoshi, Anopheles coustani, Aedes neoafricanus, Aedes simpsoni, Aedes vittatus, Anopheles pretoriensis, Anopheles pharoensis, Anopheles mascarensis, Culex bitaeniorhynchus, Culex tritaeniorhynchus, Culex antennatus, and Culex poicilipes in Senegal in study period 1991-1994 (31). These successful isolations suggest a large vector range, which could indicate the potential for widespread geographic distributions as well as potential vertebrate host ranges, given the diversity of feeding preferences of these mosquitoes.

Batai virus has been isolated from cattle and human patients $(16,24,34)$. BATV has been isolated from several mosquito species as described above, and additionally in Anopheles claviger, Coquillettidia richiardii, Culex pipiens s.i.,Ochlerotatus punctor, Ochlerotatus Communis, and Ae. vexans $(72,79,80)$. BATV has also been shown to be transmitted by biting midges (Culicoides spp.) and ticks (81).

Because risk for BATV transmission has been correlated with migratory and resident bird population distributions, BATV is thought to be associated with bird-mosquito enzootic cycle similar to WNV, Usutu virus, and Sindbis virus $(72,82)$. Indeed, the migratory patterns of competent bird species likely accounts for its wide geographic distribution across Europe and Asia $(79,83)$. BATV infection is less severe in humans, though it occurred epidemically in Scandinavia in the 1960s. In addition, neutralizing antibodies have been detected in a number of cows and one farmer on coastal farms in Finland $(15,84,85)$.

\section{ASSOCIATED DISEASE}

All three viruses (BUNV, NRIV, and BATV) have been reported to infect humans and other mammals. BUNV causes mild symptoms in humans, such as fever, headache, joint pain, and rash. Symptomatic infections are more often reported in children, and immunocomprised patients may progress to severe encephalitis (12). In domestic animals, especially ruminants, infection leads to severe symptoms, such as spontaneous abortion and teratogenic effects (14). In 2013, BUNV was isolated for the first time in horses in Argentina after two horses developed neurological signs and died (2). CVV is endemic to North America and causes very severe diseases in humans and ruminants characterized by embryonic and fetal death, stillbirths, and multiple congenital malformations especially in ruminants. Humans are rarely infected by CVV, however, severe headache, nausea, vomiting, fatigue, encephalitis, and multiorgan failure have been reported in patients (86-88).

Batai virus infections in livestock results in abortions, premature births, and congenital defects $(14,16,81)$. In humans, BATV infection has been characterized as a non-descript febrile illness in Africa and Asia and associated with an influenza-like illness in Europe (72). Febrile disease, bronchopneumonia, exudative pleurisy, catarrhal and follicular tonsillitis, and acute gastritis have all been reported clinical signs associated with BATV infection in humans $(15,89)$.

Ngari virus is reported to cause severe and fatal hemorrhagic fever in humans (3). NRIV clinical manifestations are similar to those of RVFV, as seen in the Kenya and Somalia outbreaks (1998-1999) and the Mauritania outbreak (2010) (4, 17). NRIV has also been isolated from small ruminants with hemorrhagic manifestations (17).

\section{ONE HEALTH IMPLICATIONS OF BUNV, BATV, AND NRIV}

While BATV is less associated with severe human disease, it can lead to significant economic losses as it infects agriculturally important mammals and bird species (14-16, 81, 89). However, given that RVFV, BUNV, and NRIV present many similarities in their clinical manifestations, co-circulate within the same vector and/or vertebrate host ranges, and share the same ecological distribution, NRIV and BUNV might contribute to outbreaks of hemorrhagic fever in these regions of both cattle and humans. 
Indeed, there is evidence for co-circulation in Kenya (1997-1998), where RVFV and NRIV were found in respectively 23 and $27 \%$ of human hemorrhagic fever cases tested, which was the first report of BUNV causing human disease (4). In Mauritania (2010), during an ongoing RVFV outbreak in livestock, 163 serum samples (62 from camels, 8 from cattle, and 93 from small ruminants) were tested for NRIV, and two goat samples were positive for NRIV (32). In addition, one of these two samples was also IgM positive for RVFV, suggesting a recent (possibly co-) infection of RVFV (32). These data suggest that in areas, where RVFV is reported but not confirmed or where the etiologic agent has not been molecularly confirmed, BUNV and NRIV should be included in a differential diagnostic panel for hemorrhagic fevers of humans and animals $(1,3)$.

That being said, the diagnostic capabilities available for Orthobunyaviruses in general are limited. Detection of nucleic acid has been utilized and is capable of differentiating between BATV, NRIV, and BUNV, but requires multiple genes to be amplified. And inherent in this method is the assumption that there are no co-infections of NRIV and one of its parental viruses, as theoretically, a co-infection of BATV and BUNV would give the same pcr read-out as NRIV. Thus, serological assays are needed to detect circulation of these viruses. Cross-neutralization among these viruses is not limited to these three, and traditional PRNT methods are likely to be unable to distinguish to the species level (28). In addition, there is a commercially available nucleotide and antibody bundle that was developed for Cache Valley Fever virus (Discovery Antibodies, UK), a strain of BUNV, which purports to cross-react with BATV. Thus, while diagnostic capability for these three Orthobunyaviruses exists, whether or not there is an ability to definitively identify which virus is the agent remains unclear.

In addition to diagnostic capabilities, there is a better need to understand control and prevention of transmission. A first step in this process is identifying the mosquito vectors of medical and veterinary importance. To that point, the geographic distribution(s) of these three viruses should be better characterized in effort to accurately assess which mosquito vectors could transmit. Additionally, comparative vector competence studies should be conducted in efforts to elucidate the relative transmission potential of these three viruses. Although BATV is mainly defined as European/Asian virus and has only once been isolated in Africa, it may be present in several other countries in Africa, but underreported, since NRIV has only been isolated in Africa and BATV is its presumptive parent. After identification of likely vectors, appropriate control methods can be implemented, such as additional spraying efforts and behavior modification and education programs. And since the life cycles of vectors are closely related to climatic conditions, the role of climate change in the continued circulation, the potential for altered and expanded

\section{REFERENCES}

1. Briese T, Bird B, Kapoor V, Nichol ST, Lipkin WI. Batai and Ngari viruses: $\mathrm{M}$ segment reassortment and association with severe febrile disease outbreaks in East Africa. J Virol (2006) 80(11):5627-30. doi:10.1128/JVI. 02448-05

2. Tauro LB, Rivarola ME, Lucca E, Mariño B, Mazzini R, Cardoso JF, et al. First isolation of Bunyamwera virus (Bunyaviridae family) from horses with geographic distributions, and seasonality of transmission should be considered in all prevention campaigns.

\section{CONCLUSION}

The similarity between these viruses suggests that differential diagnosis of febrile and/or hemorrhagic diseases should be done carefully in areas where these viruses are likely underreported. The overlap in distribution, vertebrate, and vector hosts, and similarity in clinical presentation makes clinical identification of disease agents difficult. Since NRIV has been isolated twice during concurrent RVFV outbreaks, the co-circulation of these two viruses and their respective contributions to the burden of human and animal disease needs to be better understood. These viruses pose potential threats to animal health, food security, and human public health. Thus, a One Health approach to the promotion of understanding these viruses should be undertaken to define geographic risk regions, vector control strategies, and diagnostic development. Overall, the relevance of these and other lesser-characterized Bunyaviruses can only be appropriately prioritized as these viruses are comprehensively studied.

\section{AUTHOR CONTRIBUTIONS}

All authors contributed equally to the conception of this review. $\mathrm{MD}$ and RC executed a first draft. All authors contributed equally to the final draft and editing of the manuscript.

\section{FUNDING}

This work is supported by the USDA National Institute of Food and Agriculture, project \#LAV3748, accession \#1015690. The contents are solely the responsibility of the authors and do not necessarily represent the official views of the USDA or NIFA. Additionally, this was supported in part upon work supported by the United States Agency for International Development, as part of the Feed the Future initiative, under the CGIAR Fund, award number BFS-G-11-00002, and the predecessor fund the Food Security and Crisis Mitigation II grant, award number EEM-G-00-04-00013.

\section{SUPPLEMENTARY MATERIAL}

The Supplementary Material for this article can be found online at https://www.frontiersin.org/articles/10.3389/fvets.2018.00069/ full\#supplementary-material.

TABLE S1 | Geographic locations, coordinates, and year of report of three Orthobunyaviruses: Bunyamwera (BUNV), Bataie (BATV), and Ngari (NRIV).

neurological disease and an abortion in Argentina. Vet J (2015) 206(1):111-4. doi:10.1016/j.tvjl.2015.06.013

3. Gerrard SR, Li L, Barrett AD, Nichol ST. Ngari virus is a Bunyamwera virus reassortant that can be associated with large outbreaks of hemorrhagic fever in Africa. J Virol (2004) 78(16):8922-6. doi:10.1128/JVI.78.16.8922-8926.2004

4. Bowen MD, Trappier SG, Sanchez AJ, Meyer RF, Goldsmith CS, Zaki SR, et al. A reassortant bunyavirus isolated from acute hemorrhagic fever cases in Kenya and Somalia. Virology (2001) 291(2):185-90. doi:10.1006/viro.2001.1201 
5. Groseth A, Matsuno K, Dahlstrom E, Anzick SL, Porcella SF, Ebihara H. Complete genome sequencing of four geographically diverse strains of Batai virus. J Virol (2012) 86(24):13844-5. doi:10.1128/JVI.02641-12

6. Fuller F, Bishop DH. Identification of virus-coded nonstructural polypeptides in bunyavirus-infected cells. J Virol (1982) 41(2):643-8.

7. Borucki MK, Chandler LJ, Parker BM, Blair CD, Beaty BJ. Bunyavirus superinfection and segment reassortment in transovarially infected mosquitoes. J Gen Virol (1999) 80(Pt 12):3173-9. doi:10.1099/0022-1317-80-12-3173

8. Gentsch J, Bishop DH. Recombination and complementation between temperature-sensitive mutants of a bunyavirus, snowshoe hare virus. J Virol (1976) 20(1):351-4.

9. Hontz RD, Guevara C, Halsey ES, Silvas J, Santiago FW, Widen SG, et al. Itaya virus, a novel orthobunyavirus associated with human febrile illness, Peru. Emerg Infect Dis (2015) 21(5):781-8. doi:10.3201/eid2105.141368

10. Aguilar PV, Barrett AD, Saeed MF, Watts DM, Russell K, Guevara C, et al. Iquitos virus: a novel reassortant orthobunyavirus associated with human illness in Peru. PLoS Negl Trop Dis (2011) 5(9):e1315. doi:10.1371/journal. pntd.0001315

11. Odhiambo C, Venter M, Limbaso K, Swanepoel R, Sang R. Genome sequence analysis of in vitro and in vivo phenotypes of Bunyamwera and Ngari virus isolates from northern Kenya. PLoS One (2014) 9(8):e105446. doi:10.1371/ journal.pone. 0105446

12. Ashford RW. Encyclopedia of Arthropod-Transmitted Infections of Man and Domesticated Animals. London: CABI (2001).

13. Kokernot RH, Smithburn KC, De Meillon B, Paterson HE. Isolation of Bunyamwera virus from a naturally infected human being and further isolations from Aedes (Banksinella) circumluteolus theo. Am J Trop Med Hyg (1958) 7(6):579-84. doi:10.4269/ajtmh.1958.7.579

14. Rodrigues Hoffmann A, Dorniak P, Filant J, Dunlap KA, Bazer FW, de la Concha-Bermejillo A, et al. Ovine fetal immune response to Cache valley virus infection. J Virol (2013) 87(10):5586-92. doi:10.1128/JVI.01821-12

15. Medlock JM, Snow KR, Leach S. Possible ecology and epidemiology of medically important mosquito-borne arboviruses in Great Britain. Epidemiol Infect (2007) 135(3):466-82. doi:10.1017/S0950268806007047

16. Yanase T, Kato T, Yamakawa M, Takayoshi K, Nakamura K, Kokuba T, et al. Genetic characterization of Batai virus indicates a genomic reassortment between orthobunyaviruses in nature. Arch Virol (2006) 151(11):2253-60. doi:10.1007/s00705-006-0808-x

17. Jäckel S, Eiden M, El Mamy BO, Isselmou K, Vina-Rodriguez A, Doumbia B, et al. Molecular and serological studies on the Rift Valley fever outbreak in Mauritania in 2010. Transbound Emerg Dis (2013) 60(Suppl 2):31-9. doi:10.1111/tbed.12142

18. Szemiel AM, Failloux AB, Elliott RM. Role of Bunyamwera orthobunyavirus NSs protein in infection of mosquito cells. PLoS Negl Trop Dis (2012) 6(9):e1823. doi:10.1371/journal.pntd.0001823

19. Riblett AM, Doms RW. Making bunyaviruses talk: interrogation tactics to identify host factors required for infection. Viruses (2016) 8(5):E130. doi:10.3390/v8050130

20. Kifaro EG, Nkangaga J, Joshua G, Sallu R, Yongolo M, Dautu G, et al. Epidemiological study of Rift valley fever virus in Kigoma, Tanzania. Onderstepoort J Vet Res (2014) 81(2):E1-5. doi:10.4102/ojvr.v81i2.717

21. Nanyingi MO, Munyua P, Kiama SG, Muchemi GM, Thumbi SM, Bitek AO, et al. A systematic review of Rift valley fever epidemiology 1931-2014. Infect Ecol Epidemiol (2015) 5:28024. doi:10.3402/iee.v5.28024

22. Bird BH, McElroy AK. Rift valley fever virus: unanswered questions. Antiviral Res (2016) 132:274-80. doi:10.1016/j.antiviral.2016.07.005

23. Galindo-Cardiel I, Busquets N, Velarde R, Abad FX, Solanes D, Rivas R, et al. Lymphoplasmacytic endotheliitis and anterior uveitis in sheep infected experimentally with rift valley fever virus. J Comp Pathol (2012) 146(1):40-3. doi:10.1016/j.jcpa.2011.03.013

24. Nashed NW, Olson JG, el-Tigani A. Isolation of Batai virus (Bunyaviridae: Bunyavirus) from the blood of suspected malaria patients in Sudan. Am J Trop Med Hyg (1993) 48(5):676-81. doi:10.4269/ajtmh.1993.48.676

25. Amexo M, Tolhurst R, Barnish G, Bates I. Malaria misdiagnosis: effects on the poor and vulnerable. Lancet (2004) 364(9448):1896-8. doi:10.1016/ S0140-6736(04)17446-1

26. Fauci AS, Morens DM. Zika virus in the Americas - yet another arbovirus threat. N Engl J Med (2016) 374(7):601-4. doi:10.1056/NEJMp1600297
27. Leparc-Goffart I, Nougairede A, Cassadou S, Prat C, De Lamballerie X. Chikungunya in the Americas. Lancet (2014) 383(9916):514. doi:10.1016/ S0140-6736(14)60185-9

28. Hunt AR, Calisher $\mathrm{CH}$. Relationships of Bunyamwera group viruses by neutralization. Am J Trop Med Hyg (1979) 28(4):740-9. doi:10.4269/ajtmh. 1979.28 .740

29. Smithburn KC, Haddow AJ, Mahaffy AF. A neurotropic virus isolated from Aedes mosquitoes caught in the Semliki forest. Am J Trop Med Hyg (1946) 26:189-208. doi:10.4269/aitmh.1946.s1-26.189

30. Wertheim HF, Horby P, Woodall JP, editors. Atlas of Human Infectious Diseases. Chichester: John Wiley \& Sons (2012).

31. Zeller HG, Diallo M, Angel G, Traoré-Lamizana M, Thonnon J, Digoutte JP, et al. [Ngari virus (Bunyaviridae: Bunyavirus). First isolation from humans in Senegal, new mosquito vectors, its epidemiology]. Bull Soc Pathol Exot (1996) 89(1):12-6

32. Eiden M, Vina-Rodriguez A, El Mamy BO, Isselmou K, Ziegler U, Höper D, et al. Ngari virus in goats during Rift valley fever outbreak, Mauritania, 2010. Emerg Infect Dis (2014) 20(12):2174-6. doi:10.3201/eid2012.140787

33. Groseth A, Weisend C, Ebihara H. Complete genome sequencing of mosquito and human isolates of Ngari virus. J Virol (2012) 86(24):13846-7. doi:10.1128/ JVI.02644-12

34. Liu H, Shao XQ, Hu B, Zhao JJ, Zhang L, Zhang HL, et al. Isolation and complete nucleotide sequence of a Batai virus strain in Inner Mongolia, China. Virol J (2014) 11:138. doi:10.1186/1743-422X-11-138

35. Karabatsos NK. International Catalogue of Arbovirus, Including Certain Other Viruses of Vertebrates. San Antonio, TX: American Society of Tropical Medicine and Hygiene (1985).

36. Singh KR, Pavri KM. Isolation of Chittoor virus from mosquitoes and demonstration of serological conversions in sera of domestic animals at Manjri, Poona, India. Indian J Med Res (1966) 54:220-4.

37. Gaidamovich SY, Obukhova VR, Vinograd AI, Klisenko GA, Melnikova EE. Olkya - an arbovirus of the Bunyamwera group in the U.S.S.R. Acta Virol (1973) 17(5):444.

38. Cavazzana M, Six E, Lagresle-Peyrou C, André-Schmutz I, Hacein-Bey-Abina S. Gene therapy for X-linked severe combined immunodeficiency: where do we stand? Hum Gene Ther (2016) 27(2):108-16. doi:10.1089/hum.2015.137

39. Hollidge BS, Gonzalez-Scarano F, Soldan SS. Arboviral encephalitides: transmission, emergence, and pathogenesis. JNeuroimmune Pharmacol (2010) 5(3):428-42. doi:10.1007/s11481-010-9234-7

40. Altizer S, Bartel R, Han BA. Animal migration and infectious disease risk. Science (2011) 331(6015):296-302. doi:10.1126/science.1194694

41. Mohamed M, McLees A, Elliott RM. Viruses in the Anopheles A, Anopheles B, and Tete serogroups in the Orthobunyavirus genus (family Bunyaviridae) do not encode an NSs protein. J Virol (2009) 83(15):7612-8. doi:10.1128/ JVI.02080-08

42. Elliot RM, Schmaljohn CS. Bunyaviruses. In: Fields Virology. Philadelphia: Lippincott Williams \& Wilkins (2013). p. 1244-82.

43. Scherer WF. International catalogue of arboviruses including certain other viruses of vertebrates. Am J Trop Med Hyg (1976) 25:204-5. doi:10.4269/ ajtmh.1976.25.204

44. Tikasingh ES, Spence L, Downs WG. The use of adjuvant and sarcoma 180 cells in the production of mouse hyperimmune ascitic fluids to arboviruses. Am J Trop Med Hyg (1966) 15(2):219-26. doi:10.4269/ajtmh.1966.15.219

45. Abraham A, Jacobsohn DA, Bollard CM. Cellular therapy for sickle cell disease. Cytotherapy (2016) 18(11):1360-9. doi:10.1016/j.jcyt.2016.06.011

46. Calisher $\mathrm{CH}$. History, classification, and taxonomy of viruses in the family Bunyaviridae. In: Elliott RM, editor. The Bunyaviridae. US: Springer (1996). p. 1-17.

47. Causey OR, Causey CE, Maroja OM, Macedo DG. The isolation of arthropod-borne viruses, including members of two hitherto undescribed serological groups, in the Amazon region of Brazil. Am J Trop Med Hyg (1961) 10:227-49. doi:10.4269/ajtmh.1961.10.227

48. Casals J, Clarke DH. Arboviruses other than group A and B. In: Horsefall FL, Tamm L, editors. Viral and Rickettsial Infections of Man. Philadelphia: Lippincott (1965).

49. Southam CM, Moore AE. West Nile, Ilheus, and Bunyamwera virus infections in man. Am J Trop Med Hyg (1951) 31(6):724-41. doi:10.4269/ajtmh.1951. s1-31.724 
50. Odhiambo C, Venter M, Chepkorir E, Mbaika S, Lutomiah J, Swanepoel R, et al. Vector competence of selected mosquito species in Kenya for Ngari and Bunyamwera viruses. J Med Entomol (2014) 51(6):1248-53. doi:10.1603/ ME14063

51. Odhiambo C, Venter M, Swanepoel R, Sang R. Orthobunyavirus antibodies among humans in selected parts of the Rift valley and northeastern Kenya. Vector Borne Zoonotic Dis (2015) 15(5):329-32. doi:10.1089/vbz.2014.1760

52. Elliott RM. The Bunyaviridae. New York: Springer Science \& Business Media (2013).

53. Kuhn JH, Wiley MR, Rodriguez SE, Bào Y, Prieto K, Travassos da Rosa A, et al. Genomic characterization of the genus nairovirus (family bunyaviridae). Viruses (2016) 8(6):164. doi:10.3390/v8060164

54. Adams MJ, Lefkowitz EJ, King AMQ, Harrach B, Harrison RL, Knowles NJ, et al. Changes to taxonomy and the International Code of Virus Classification and Nomenclature ratified by the International Committee on Taxonomy of Viruses (2017). Arch Virol (2017) 162(8):2505-38. doi:10.1007/s00705017-3358-5

55. Elliott RM. Orthobunyaviruses: recent genetic and structural insights. Nat Rev Microbiol (2014) 12(10):673-85. doi:10.1038/nrmicro3332

56. King AM, Lefkowitz E, Adams MJ, Carstens EB, editors. Virus Taxonomy: Ninth Report of the International Committee on Taxonomy of Viruses. London: Elsevier (2011).

57. Fuller F, Bhown AS, Bishop DH. Bunyavirus nucleoprotein, N, and a non-structural protein, NSS, are coded by overlapping reading frames in the S RNA. J Gen Virol (1983) 64(Pt 8):1705-14. doi:10.1099/0022-1317-64-8-1705

58. Elliott RM. Nucleotide sequence analysis of the large (L) genomic RNA segment of Bunyamwera virus, the prototype of the family Bunyaviridae. Virology (1989) 173:426-36. doi:10.1016/0042-6822(89)90555-2

59. Gentsch JR, Bishop DL. M viral RNA segment of bunyaviruses codes for two glycoproteins, G1 and G2. J Virol (1979) 30(3):767-70.

60. Elliott RM. Identification of nonstructural proteins encoded by viruses of the Bunyamwera serogroup (family Bunyaviridae). Virology (1985) 143:119-26. doi:10.1016/0042-6822(85)90101-1

61. Walter CT, Barr JN. Bunyamwera virus can repair both insertions and deletions during RNA replication. RNA (2010) 16(6):1138-45. doi:10.1261/ rna. 1962010

62. Phoenix I, Lokugamage N, Nishiyama S, Ikegami T. Mutational analysis of the Rift valley fever virus glycoprotein precursor proteins for Gn protein expression. Viruses (2016) 8(6):E151. doi:10.3390/v8060151

63. Barr JN, Elliott RM, Dunn EF, Wertz GW. Segment-specific terminal sequences of Bunyamwera bunyavirus regulate genome replication. Virology (2003) 311(2):326-38. doi:10.1016/S0042-6822(03)00130-2

64. Barr JN, Wertz GW. Role of the conserved nucleotide mismatch within 3'- and 5 '-terminal regions of Bunyamwera virus in signaling transcription. $J$ Virol (2005) 79(6):3586-94. doi:10.1128/JVI.79.6.3586-3594.2005

65. Kohl A, Dunn EF, Lowen AC, Elliott RM. Complementarity, sequence and structural elements within the 3 ' and 5' non-coding regions of the Bunyamwera orthobunyavirus S segment determine promoter strength. J Gen Virol (2004) 85(Pt 11):3269-78. doi:10.1099/vir.0.80407-0

66. Mazel-Sanchez B, Elliott RM. Attenuation of Bunyamwera orthobunyavirus replication by targeted mutagenesis of genomic untranslated regions and creation of viable viruses with minimal genome segments. J Virol (2012) 86(24):13672-8. doi:10.1128/JVI.02253-12

67. van Knippenberg I, Elliott RM. Flexibility of bunyavirus genomes: creation of an orthobunyavirus with an ambisense S segment. J Virol (2015) 89(10):5525-35. doi:10.1128/JVI.03595-14

68. Weber F, Bridgen A, Fazakerley JK, Streitenfeld H, Kessler N, Randall RE, et al. Bunyamwera bunyavirus nonstructural protein NSs counteracts the induction of alpha/beta interferon. J Virol (2002) 76(16):7949-55. doi:10.1128/ JVI.76.16.7949-7955.2002

69. Elliott RM. The Bunyaviridae. New York, NY: Plenum Press (1996).

70. Jin M, Park J, Lee S, Park B, Shin J, Song KJ, et al. Hantaan virus enters cells by clathrin-dependent receptor-mediated endocytosis. Virology (2002) 294(1):60-9. doi:10.1006/viro.2001.1303

71. Santos RI, Rodrigues AH, Silva ML, Mortara RA, Rossi MA, Jamur MC, et al. Oropouche virus entry into HeLa cells involves clathrin and requires endosomal acidification. Virus Res (2008) 138(1-2):139-43. doi:10.1016/j. virusres.2008.08.016
72. Lozach PY, Mancini R, Bitto D, Meier R, Oestereich L, Overby AK, et al. Entry of bunyaviruses into mammalian cells. Cell Host Microbe (2010) 7(6):488-99. doi:10.1016/j.chom.2010.05.007

73. Simon M, Johansson C, Mirazimi A. Crimean-Congo hemorrhagic fever virus entry and replication is clathrin-, $\mathrm{pH}$ - and cholesterol-dependent. J Gen Virol (2009) 90(Pt 1):210-5. doi:10.1099/vir.0.006387-0

74. Albornoz A, Hoffmann AB, Lozach PY, Tischler ND. Early Bunyavirus-host cell interactions. Viruses (2016) 8(5):143. doi:10.3390/v8050143

75. Phoenix I, Nishiyama S, Lokugamage N, Hill TE, Huante MB, Slack OA, et al. $\mathrm{N}$-glycans on the Rift valley fever virus envelope glycoproteins Gn and Gc redundantly support viral infection via DC-SIGN. Viruses (2016) 8(5):E149. doi:10.3390/v8050149

76. Newton SE, Short NJ, Dalgarno L. Bunyamwera virus replication in cultured Aedes albopictus (mosquito) cells: establishment of a persistent viral infection. J Virol (1981) 38(3):1015-24.

77. Hardestam J, Simon M, Hedlund KO, Vaheri A, Klingström J, Lundkvist A. Ex vivo stability of the rodent-borne Hantaan virus in comparison to that of arthropod-borne members of the Bunyaviridae family. Appl Environ Microbiol (2007) 73(8):2547-51. doi:10.1128/AEM.02869-06

78. Pepin M, Bouloy M, Bird BH, Kemp A, Paweska J. Rift valley fever virus (Bunyaviridae: Phlebovirus): an update on pathogenesis, molecular epidemiology, vectors, diagnostics and prevention. Vet Res (2010) 41(6):61. doi:10.1051/ vetres $/ 2010033$

79. Hubalek Z. Mosquito-borne viruses in Europe. Parasitol Res (2008) 103(Suppl 1): S29-43. doi:10.1007/s00436-008-1064-7

80. Francy DB, Jaenson TG, Lundström JO, Schildt EB, Espmark A, Henriksson B, et al. Ecologic studies of mosquitoes and birds as hosts of Ockelbo virus in Sweden and isolation of Inkoo and Batai viruses from mosquitoes. Am J Trop Med Hyg (1989) 41(3):355-63. doi:10.4269/ajtmh.1989.41.355

81. Dilcher M, Sall AA, Hufert FT, Weidmann M. Clarifying Bunyamwera virus riddles of the past. Virus Genes (2013) 47(1):160-3. doi:10.1007/ s11262-013-0918-y

82. Hubálek Z, Halouzka J. Arthropod-Borne Viruses of Vertebrates in Europe. (Vol. 30). Brno: Acta Scientarum Naturalium Academiae Scientiarum Bohemicae (1996). p. 1-95.

83. Jöst H, Bialonski A, Storch V, Günther S, Becker N, Schmidt-Chanasit J. Isolation and phylogenetic analysis of Sindbis viruses from mosquitoes in Germany. J Clin Microbiol (2010) 48(5):1900-3. doi:10.1128/JCM.00037-10

84. Brummer-Korvenkontio M, Saikku P. Mosquito-borne viruses in Finland. Med Biol (1975) 53(5):279-81.

85. Brummer-Korvenkontio M. Batai (Calovo) arbovirus neutralising antibodies in Finland. Ann Med Exp Biol Fenn (1973) 51(4):158-61.

86. Armstrong PM, Andreadis TG, Anderson JF. Emergence of a new lineage of Cache valley virus (Bunyaviridae: Orthobunyavirus) in the Northeastern United States. Am JTrop Med Hyg (2015) 93(1):11-7. doi:10.4269/ ajtmh.15-0132

87. Edwards JF. Cache valley virus. Vet Clin North Am Food Anim Pract (1994) 10(3):515-24. doi:10.1016/S0749-0720(15)30536-3

88. Campbell GL, Mataczynski JD, Reisdorf ES, Powell JW, Martin DA, Lambert AJ, et al. Second human case of Cache valley virus disease. Emerg Infect Dis (2006) 12(5):854-6. doi:10.3201/eid1205.051625

89. Sluka F. The clinical picture of the Calovo virus infection, in Arboviruses of the California complex and the Bunyamwera group. Proceedings of the Slovak Academy of Sciences Symposium. Bratislava (1969). p. 337-9.

Conflict of Interest Statement: The authors declare that the research was conducted in the absence of any commercial or financial relationships that could be construed as a potential conflict of interest.

The reviewer KD and handling Editor declared their shared affiliation.

Copyright ( 2018 Dutuze, Nzayirambaho, Mores and Christofferson. This is an open-access article distributed under the terms of the Creative Commons Attribution License (CC BY). The use, distribution or reproduction in other forums is permitted, provided the original author(s) and the copyright owner are credited and that the original publication in this journal is cited, in accordance with accepted academic practice. No use, distribution or reproduction is permitted which does not comply with these terms. 